\title{
Molecular Localization and Developmental Expression of the otu Locus of Drosophila melanogaster
}

\author{
PAMELA K. MULLIGAN, ${ }^{1}$ J. DAWSON MOHLER, ${ }^{2}$ AND LAURA J. KALFAYAN ${ }^{1 *}$ \\ Department of Biochemistry, University of North Carolina at Chapel Hill, Chapel Hill, North Carolina $27514,{ }^{1}$ and \\ Department of Biology, University of Iowa, Iowa City, Iowa $52242^{2}$
}

Received 5 October 1987/Accepted 5 January 1988

\begin{abstract}
The female-sterile ovarian tumor gene, otu, is located in cytological region 7F1 on the Drosophila melanogaster chromosome map. We have mapped the gene at the molecular level by using four dysgenic alleles and two revertant derivatives of these alleles as well as an ethyl methanesulfonate-induced allele. The insertional (dysgenic) changes were all associated with one restriction fragment, and its size was restored after phenotypic reversion. One ethyl methanesulfonate-induced allele had a deletion in the restriction fragment adjacent (distal) to the fragment altered in the insertional alleles. These two restriction fragments were immediately adjacent to the $\mathbf{3 8}$ chorion gene. Associated with the two altered restriction fragments were two RNA species, an abundant 3.2-kilobase $(k b)$ poly $(\mathbf{A})^{+}$RNA and a minor 4.0-kb RNA. Several other less-abundant RNA species were detectable with more-sensitive single-stranded RNA probes. The otu gene was transcribed proximal to distal relative to the centromere; this was opposite to the direction of transcription of the adjacent $s 38$ gene. During development, the 3.2-kb RNA was absent in larvae, first appeared in the pupal stages, and persisted in adult females, in which it was most prevalent in the ovaries. The DNA that hybridized to the 3.2-kb ovarian RNA hybridized to four different RNAs found in the testes but not in the rest of the adult male. These testis-enriched RNAs were transcribed from the same strand of DNA as the ovarian transcripts.
\end{abstract}

Our understanding of germ cell determination and differentiation in Drosophila melanogaster oogenesis is derived largely from morphological and genetic studies. During oogenesis, a single apical ovarian cell, the germarial cystoblast, undergoes four incomplete cell divisions to produce a syncytium of 16 interconnected cystocytes. One of these cystocytes differentiates into an oocyte (19), while the remaining 15 become the nurse cells that nourish the growing oocyte via intercellular cytoplasmic bridges $(8,26-28)$ and provide it with RNAs and proteins that will be required during early embryogenesis (30).

Of central interest in germ cell development is the mechanism by which 1 cystocyte develops into an oocyte and the other 15 cystocytes develop into nurse cells. Within a 16-cell syncytium, the number of intercellular bridges varies from one to four per cell, with only 2 of the 16 cystocytes having four bridges. Immediately after the formation of the 16-cell cluster, both four-canal cells enter meiotic prophase $(27,28)$. However, one of these cells subsequently enters the nurse cell developmental pathway, while the other develops as an oocyte. It therefore appears that four cytoplasmic bridges are a necessary but not sufficient prerequisite for determination of oocyte development.

We are interested in the early events of oogenesis and specifically in genes that regulate the morphogenesis of the germ cells themselves. The otu gene is one of several genes whose products are required for the determination and differentiation of oocytes and nurse cells $(19,21,22,25)$. Homozygous mutant otu females are sterile and display a variety of abnormalities with respect to oocyte and nurse cell development. Heterozygous (otu/otu $\left.{ }^{+}\right)$females, hemizygous mutant males, and hemizygous wild-type $\left[\right.$ ot $^{+} / \mathrm{Df}($ otu $\left.)\right]$ females are fertile $(6,21,23-25,37)$. Clonal analysis studies of a mutant allele of this gene, $f s(1) 116\left(\right.$ otu $\left.^{3}\right)$, showed that the

\footnotetext{
* Corresponding author.
}

gene is expressed, and its product is required, in the germ cells of the ovary (48). Two independent studies have also shown that the alleles $o t u^{4}$ and $o t u^{7}$ are germ cell autonomous (unpublished data [21]).

The otu locus has been mapped to position 23.2 on the genetic map and in region 7F1 on the cytological map by using the allele $o t u^{2}(21)$. A total of 17 recessive alleles (otu ${ }^{I}$ through $o t u^{17}$ ) have been generated by ethyl methanesulfonate (EMS)-induced mutagenesis in different laboratories (13, 21, 24; M. E. Digan, Ph.D. thesis, Indiana University, Bloomington, 1980). In addition, we have generated four otu alleles $\left(o t u^{P I}\right.$ through $o t u^{P 4}$ ) via hybrid dysgenesis-induced mutagenesis. otu alleles have been divided into the following three major classes on the basis of the behavior of the stem-line oogonia in homozygous mutant females (21). (i) The quiescent (QUI) class contains otu alleles which are defective in oogonial proliferation and contain chamberless ovarioles. (ii) Alleles in the oncogenic (ONC) class produce cystoblasts and cystocytes which fail to differentiate into oocyte and nurse cells. Females homozygous for the ONC alleles develop ovarian tumors made up of hundreds to thousands of dividing cystocytes. (iii) In the differentiated (DIF) class are alleles which produce cystocytes which differentiate into pseudonurse cells, nurse cells, or oocytes, but in which the egg chambers never complete development.

This study is aimed at improving knowledge of the molecular events associated with early oogenesis in $D$. melanogaster. Since mutations at the otu locus effect a variety of phenotypic changes in the ovary, the ot $^{+}$gene product may be required not only for female germ cell formation but also for other events, such as cessation of cystocyte division and the differentiation of the oocyte and nurse cell nuclei. As a first step toward gaining an understanding of how this gene acts during oogenesis, we have identified a genomic DNA segment containing $\mathrm{otu}^{+}$and have examined the expression of this gene during development and in a variety of tissues. 


\section{MATERIALS AND METHODS}

Stock and culture conditions. Flies were reared on a high-yeast medium (10) at $25^{\circ} \mathrm{C}$ and on a standard cornmealmolasses-brewer's yeast-agar medium with propionic acid to inhibit mold growth at $18^{\circ} \mathrm{C}$ for genetic and molecular studies, respectively. Each otu allele was maintained in a balanced stock, and homozygotes were obtained from cultures of the respective strains.

Hybrid-dysgenic mutagenesis and screening for otu $\mathbf{P}$ alleles. The ot $u^{P}$ mutations were recovered in the descendants of $\mathbf{M} \times \mathbf{P}$ matings. The $\mathbf{P}$ strains were obtained from William Engels and are identified as $\pi 2$, Inbred cage 3, 8.31.15, and 78.61. The $M$ strains were from stocks synthesized at Iowa and were $s n^{3} l z^{50 e}$ in experiment 1 and an attached-X strain with $C(I) A, y$ in experiment 2 . For mutagenesis studies, $\mathrm{F}_{1}$ dysgenic flies from the $\mathbf{M} \times \mathbf{P}$ crosses were mated to yield male progeny (hybrid dysgenic), each with the potential of carrying new sex-linked female-sterile mutations. To detect any new female-sterile mutations which occurred at the otu locus and its close neighbors and to establish balanced strains of such mutations, each male was mated to females carrying $D f(1) R A 2$ and a Bar-marked balancer $(B)$. The progeny of this mating included $B^{+}$females and Bar-eyed females. The $B^{+}$females were tested for fertility to reveal any new female-sterile mutations in the region uncovered by the deficiency, which is 7D10 through $8 \mathrm{~A} 4.5$. The $B$ siblings were used to make the balanced stocks of each new mutation. In experiment 1 , the $\mathrm{M} \times \mathrm{P} \mathrm{F}_{1}$ dysgenic parents of the hybrid dysgenic males were females; in experiment 2 , they were males.

Two fertile alleles were derived as reverse mutations from $o t u^{P 1}$ and $o t u^{P 2}$. They were discovered as fertile females from test matings of $o t u^{2} \times o t u^{P}$ made shortly after these mutations were first discovered. The revertant alleles are the following: (i) $o t u^{P R I}$ from four $y c v$ ot $u^{2} l z^{50 e} / s^{3}$ ot $u^{P I}$ females and (ii) otu ${ }^{P R 2}$ from a single y $c v$ ot $u^{2} l z^{50 e} / s n^{3} o t u^{P 2}$ $l z^{50 e}$ female. Because $o t u^{P R 2}$ appeared first in females with mosaic ovaries, the mutation presumably arose in the course of the germ line development of that female. The mutation of $o t u^{P R I}$ apparently happened no later than in the male parent of the tested females. Stocks of each mutation were established from appropriately marked individuals in the progeny of the fertile females. To control for the possibility that $o t u^{2}$ was inadvertently chosen, each presumptively revertant allele was later tested in the genotype $D f(I) R A 2 /$ ot $^{P R}$. In each case, the females were fertile, which would not be so of $D f(1) R A 2 /$ otu $^{2}$ contaminants.

Preparation of nucleic acids. Genomic Drosophila DNA was prepared from frozen adult flies by the method of Kidd et al. (18). Plasmid DNA was purified on cesium gradients by standard methods $(9,15)$, and recombinant phage DNA was prepared from plate lysates on cesium chloride step gradients (45). The recombinant phage clones $\lambda 15, \lambda 403$, and $\lambda 1406$ were generously provided by A. Spradling (43) and originally were from the Maniatis Drosophila genomic library (32).

RNAs were prepared from adults, sexed larvae, pupae, and hand-dissected adult tissues (ovary, testis, head, and thorax) by homogenization in glass tissue grinders (Wheaton Industries), followed by RNA purification as previously described (47). Poly(A) ${ }^{+}$and poly(A) ${ }^{-}$RNAs were obtained by oligo(dT)-cellulose (type 3; Collaborative Research, Inc.) column chromatography (1).

Filter hybridizations. DNA was digested with restriction enzymes (New England BioLabs, Inc.), resolved on $1 \%$ agarose gels, transferred to nitrocellulose filters (BA85; Schleicher \& Schuell, Inc.) by the method of Southern (42), and hybridized to heat-denatured nick-translated probes. The filters were hybridized at $65^{\circ} \mathrm{C}$ in a mixture containing $2 \times \mathrm{SSC}(1 \times \mathrm{SSC}$ is $0.15 \mathrm{M} \mathrm{NaCl}$ plus $0.015 \mathrm{M}$ sodium citrate, $\mathrm{pH} 7.0$ ), $8 \times$ Denhardt solution (11), $50 \mathrm{mM}$ sodium phosphate $(\mathrm{pH} 6.8), 0.1 \%$ sodium dodecyl sulfate, $100 \mu \mathrm{g}$ of denatured salmon sperm DNA per $\mathrm{ml}$, and $1 \times 10^{6}$ to $5 \times 10^{6}$ $\mathrm{cpm}$ of nick-translated probe per $\mathrm{ml}$ for more than $16 \mathrm{~h}$. Filters were prehybridized for at least $4 \mathrm{~h}$ in hybridization buffer lacking the labeled probe. After hybridization, filters were washed at $65^{\circ} \mathrm{C}$ for $4 \mathrm{~h}$ in several changes of $0.5 \times$ SSC $-0.1 \%$ sodium dodecyl sulfate, air dried, and exposed to X-ray film (Kodak XAR-5; Eastman Kodak Co.) at $-80^{\circ} \mathrm{C}$.

The RNAs were size fractionated by electrophoresis on $1 \%$ agarose gels with formaldehyde as described previously $(17,36)$. RNA was transferred to nitrocellulose filters in $20 \times$ SSC without pretreatment of the gels, essentially as described previously (46). RNAs were hybridized to nicktranslated probes under the prehybridization and hybridization conditions described previously (36), except that $8 \times$ Denhardt solution was substituted for $5 \times$ Denhardt solution in the buffer. After hybridization, the filters were washed at $65^{\circ} \mathrm{C}$ and exposed to X-ray film.

Prehybridization and hybridization of RNA filters to single-stranded RNA probes and the subsequent washes were done by the methods of Zinn et al. (49), except that dextran sulfate was omitted from the hybridization buffer.

Preparation of radiolabeled nucleic acids. Single-stranded $\left[{ }^{32}\right.$ P]RNA was made by the method of Melton et al. (34) with some modifications. Plasmid templates were linearized with restriction enzymes, phenol extracted, and ethanol precipitated before transcription with RNA polymerases. DNA was transcribed at $37^{\circ} \mathrm{C}$ for $1 \mathrm{~h}$ in a $20-\mu$ l reaction mixture containing $1 \mu \mathrm{g}$ of DNA; $0.5 \mathrm{mM}$ each of ATP, UTP, and GTP; $100 \mu \mathrm{Ci}$ of $\left[\alpha-{ }^{32} \mathrm{P}\right] \mathrm{CTP}(800 \mathrm{Ci} / \mathrm{mmol}$; Amersham Corp.); $40 \mathrm{mM}$ Tris (pH 7.5); $6 \mathrm{mM} \mathrm{MgCl}_{2} ; 2 \mathrm{mM}$ spermidine; $10 \mathrm{mM}$ dithiothreitol; $100 \mu \mathrm{g}$ of bovine serum albumin per $\mathrm{ml} ; 20 \mathrm{U}$ of RNasin; and $5 \mathrm{U}$ of SP6 or T7 RNA polymerase (Promega). After RNA synthesis, the DNA template was digested with $10 \mathrm{ng}$ of RNase-free DNase (Worthington Diagnostics) per $\mu \mathrm{l}$ for $5 \mathrm{~min}$ at $37^{\circ} \mathrm{C}$. The reaction mixture was extracted with phenol-chloroform, and the radiolabeled RNA was purified from unincorporated nucleoside triphosphate by Sephadex G-50 chromatography (31). Specific activities of $2 \times 10^{8}$ to $8 \times 10^{8} \mathrm{cpm} / \mu \mathrm{g}$ were routinely obtained by this method.

DNAs were nick translated by standard techniques (33, 38).

\section{RESULTS}

Generation of hybrid-dysgenic alleles of otu. To identify the DNA from the otu locus, we used P-element mutagenesis to create mutations with elements inserted at the locus $(5,12$, 40). In the mutagenesis experiments (Table 1), of seven female-sterile mutations found in 4,724 tests, four were new $o t u$ alleles. The $o t u^{P I}$ and $o t u^{P 2}$ alleles from the first experiment were found in different lines of descent, so they were independent in origin. Similarly, the $o t u^{P 3}$ and $o t u^{P 4}$ alleles were of independent origin (see Materials and Methods).

These mutations were shown to be in the otu gene by their homozygous and hemizygous ovarian phentoypes and by complementation tests with other otu alleles. The results of the complementation tests of the $o t u^{P}$ alleles and the EMSinduced alleles, representing all three phenotypic classes (QUI, ONC, and DIF), are shown in Table 2. The otu ${ }^{P I}$ and 
TABLE 1. New sex-linked female-sterile mutations arising from hybrid dysgenesis

\begin{tabular}{|c|c|c|c|c|c|c|c|}
\hline \multirow{3}{*}{$\begin{array}{l}\text { P-mutation } \\
\text { strain }\end{array}$} & \multicolumn{3}{|c|}{ Expt 1} & \multicolumn{3}{|c|}{ Expt 2} & \multirow{3}{*}{$\begin{array}{l}\text { New otu } \\
\text { alleles }\end{array}$} \\
\hline & \multirow{2}{*}{ Sample size } & \multicolumn{2}{|c|}{$\begin{array}{l}\text { No. of new } \mathrm{fs}^{\mathbf{a}} \\
\text { mutations }\end{array}$} & \multirow{2}{*}{ Sample size } & \multicolumn{2}{|c|}{$\begin{array}{l}\text { No. of new fs } \\
\text { mutations }\end{array}$} & \\
\hline & & otu & Other & & otu & Other & \\
\hline$\pi 2$ & 1,125 & 0 & $\mathbf{0}$ & & & & \\
\hline Inbred cage 3 & 691 & 2 & 1 & 222 & 0 & 1 & $o t u^{P I}, o t u^{P 2}$ \\
\hline 8.31 .15 & 370 & 0 & 0 & 216 & 0 & 0 & \\
\hline 78.61 & 755 & 0 & 0 & 1,344 & 2 & 1 & otu $^{P 3}$, otu $^{P 4}$ \\
\hline
\end{tabular}

${ }^{a}$ fs, Female-sterile.

$o t u^{P 2}$ alleles did not complement the EMS-induced alleles in virtually all combinations. As homozygotes, each had a tumorous-ovary (ONC) phenotype. The otu ${ }^{P 3}$ flies were fertile as homozygotes, though their productivity was only $30 \%$ of that of otu $^{P 3} /$ otu $^{+}$females. The otu ${ }^{P 3} / D f(1) R A 2$ females were sterile, whereas $o t u^{P 3}$ partially complemented all EMS-induced alleles used. In these heteroallelic combinations, the productivity of ot $^{P 3}$ heterozygotes decreased as the severity of the otu allele tested increased. The otu ${ }^{P 4}$ allele (a DIF allele) partially complemented $o t u^{i 3}$ and $o t u^{4}$. In summary, all four P mutations were hypomorphic (leaky) alleles of the otu locus.

Localization of otu close to the chorion gene cluster in 7F1. Genetic mapping of the $o t u^{2}$ allele placed it 0.06 map units proximal to cor-36, a mutation in the $s 36$ chorion gene (Digan, Ph.D. thesis; J. D. Mohler, unpublished results). The $s 36$ chorion gene resides in the most distal, 4.0-kilobase (kb) EcoRI restriction fragment, shown on the genomic restriction map at 7F1 (43; Fig. 1). Given the short genetic distance between the otu gene and the $s 36$ chorion gene, we decided to look for alterations in the genomic restriction fragments of the otu mutants by using clones $\lambda 15, \lambda 403$, and $\lambda 1406$ and the subclones derived from them as probes (Fig. 1).

In each $o t u^{P}$ allele, the $0.89-\mathrm{kb}$ fragment covered by p15-0.89 (Fig. 1) and present in the parental strains was replaced by one or more larger fragments that differed in size from those of the other ot $u^{P}$ alleles (Fig. 2). The restriction fragments surrounding the 0.89-kb fragment were the same sizes as in the wild type for all $P$ alleles, suggesting that a transposable element (presumably $P$ ) had jumped into the 0.89-kb fragment under dysgenic conditions, causing the inactivation of $\mathrm{otu}^{+}$.

Two fertile revertants, otu ${ }^{P R I}$ and $o t u^{P R 2}$, were derived from $o t u^{P 1}$ and $o t u^{P 2}$, respectively (see Materials and Methods). To correlate further the presence of P-element sequences in the $0.89-\mathrm{kb}$ fragment with sterility in the ot $u^{P}$ alleles, we analyzed genomic DNAs from both revertants (Fig. 2) and found that the 0.89-kb EcoRI fragments had been restored in both cases, suggesting the complete excision of P-element sequences from this region (Fig. 2).

A similar genomic analysis of the 17 EMS-induced alleles of otu showed that the 2.9-kb EcoRI fragment adjacent to the 0.89-kb fragment (Fig. 1) also changed in one EMS-induced allele, otu ${ }^{17}$ (Fig. 3). This allele contains a deletion of approximately $2.0 \mathrm{~kb}$ in an $8.7-\mathrm{kb}$ HindIII fragment that spans the distal EcoRI site of the 2.9-kb fragment (Fig. 3). The alleles otu ${ }^{15}$ and otu $^{16}$ (Digan, Ph.D. thesis), which were induced in the same genetic background as $o t u^{17}$, are normal with respect to these fragments. These results indicate that ot $^{+}$extends into the $2.9-\mathrm{kb}$ fragment as well. We also detected some cases of restriction-fragment-length poly- morphisms apparently unrelated to $\mathrm{otu}^{+}$function. Their locations are shown in the summary figure (Fig. 7).

Hybridization of 2.9- and 0.89-kb fragments to ovarian RNAs. The subcloned fragments identified by genomic hybridization as being important for ot $^{+}$function were used to generate hybridization probes to identify filter-bound ovarian transcripts. The subclone p15-2.9 (Fig. 1) hybridized very intensely to a $3.2-\mathrm{kb}$ poly $(\mathrm{A})^{+}$transcript and, to a lesser extent, to a 4.0-kb poly (A) ${ }^{+}$RNA (Fig. 4). The same-sized transcripts were detected with p15-0.89 (Fig. 1), although the intensity of the signal was approximately 50 times lower.

Hybridization of proximal DNA fragments to a 3.2-kb RNA. To determine the extent of the $\mathrm{ot}^{+}$transcription unit, we also hybridized the DNA proximal to p15-0.89 to filter-bound ovarian RNA (Fig. 4). Faint hybridization to a 3.2-kb RNA species was detected with radiolabeled probes generated from p15-2.2 and p15-3.2 (Fig. 1 and 4). In addition, a high-molecular-weight RNA was detected by probes generated from the more-proximal subclones of $\lambda 15$.

Developmental regulation of otu $^{+}$RNA. Poly(A) ${ }^{+}$RNAs from male and female larvae, pupae, male and female adults, and adult ovaries were screened by Northern (RNA) blot hybridization to a single-stranded RNA probe made from pSP64-2.9 (Fig. 1 and 5). A 3.2-kb transcript was first detected in late pupae (Fig. 5). Two transcripts of 1.3 and 1.1 kb were also detected at this time, and the smaller of these two transcripts was found in adult males but not in adult females. The 3.2-kb transcript was also detected in RNAs from adult females, as expected, and the adult ovary contained this transcript in heavy abundance and a 4.0-kb transcript in lower abundance (Fig. 5). Several additional minor transcripts were detected with the single-stranded probe that were not detected with the nick-translated DNA probe. Surprisingly, a 3.2-kb transcript was also detected in

TABLE 2. Productivity of $o t u^{P} / o t u^{E M S}$ and $o t u^{P} / o t u^{+}$ heterozygous females

\begin{tabular}{|c|c|c|c|c|}
\hline \multirow{2}{*}{$\begin{array}{l}\text { EMS-induced } \\
\text { allele }\end{array}$} & \multicolumn{4}{|c|}{$\begin{array}{l}\text { No. of females tested/no. of female } \\
\text { offspring }^{a} \text { for allele: }\end{array}$} \\
\hline & P1 & $\mathbf{P 2}$ & P3 & P4 \\
\hline$o t u^{10}$ QUI & $13 / 0$ & $13 / 0$ & $13 / 8$ & $13 / 0$ \\
\hline$o t u^{2}$ QUI & $10 / 0$ & $10 / 0$ & $8 / 5$ & $10 / 0$ \\
\hline$o^{\prime \prime} u^{13}$ ONC & $12 / 0.1$ & $11 / 0.2$ & $13 / 62$ & $13 / 15$ \\
\hline$o t u^{9}$ ONC & $5 / 0$ & $5 / 0$ & $5 / 148$ & $5 / 0$ \\
\hline$o t u^{4}$ DIF & $5 / 0$ & $5 / 0$ & $5 / 148$ & $5 / 4$ \\
\hline$o t u^{7}$ DIF & $13 / 0$ & $13 / 0$ & $13 / 64$ & $13 / 0$ \\
\hline$o^{5}{ }^{5}$ DIF & $13 / 0$ & $9 / 0$ & $13 / 128$ & $13 / 0.2$ \\
\hline$o t u^{14} \mathrm{DIF}$ & $13 / 0$ & $13 / 0.2$ & $13 / 129$ & $12 / 0$ \\
\hline$o t u^{+}$wild type & $\mathrm{ND}^{b}$ & ND & $5 / 310$ & $5 / 279$ \\
\hline
\end{tabular}

${ }^{a}$ Mean number of female offspring from an 8-day egg-laying period. ${ }^{b} \mathrm{ND}$, Not done. 


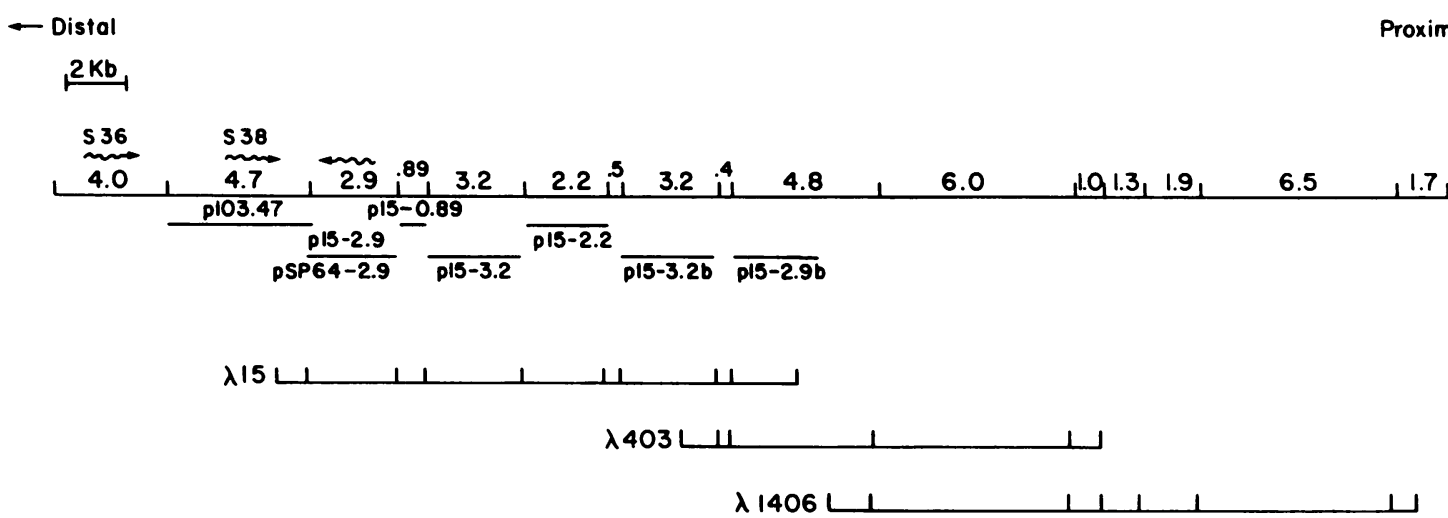

FIG. 1. EcoRI sites of the 7F region of the X chromosome. The EcoRI sites (vertical lines) are shown on the genomic map of the $7 F$ region (43). Fragment sizes are indicated in kilobases above the horizontal line which indicates the genomic DNA. The wavy arrows show the positions of three clustered transcripts and their directions of transcription. $s 36$ and $s 38$ are chorion gene positions. The genomic clones are shown beneath the genomic map. $\lambda 15, \lambda 403$, and $\lambda 1406$ were isolated previously by Spradling (43; see Materials and Methods). The subclones derived from these clones are shown under the genomic fragments and above the clones from which they are derived.

the adult male in addition to the smaller 1.1-kb male-specific transcript. The 1.1-kb transcript was first detected during the early pupal stage. Two RNAs in the 3.6- to 4.0-kb range were also present in early pupae. Since all of these transcripts were detected by a single-stranded RNA probe, all were transcribed by the same strand, and the direction of transcription was as shown in Fig. 1.

Adult-tissue-specific expression of ot $^{+}$transcripts. To analyze the tissue specificity of $\mathrm{otu}^{+}$transcription, RNAs isolated from a variety of male and female tissues were analyzed by filter hybridization with the single-stranded 2.9-kb RNA probe (Fig. 6). This probe hybridized to $\operatorname{poly}(\mathrm{A})^{+}$transcripts from ovaries and testes. The $3.2-\mathrm{kb}$ transcript present in the ovaries was absent in the testes. Instead, the testes showed a 1.1-kb transcript and three to four other transcripts in the 3.5- to $4.5-\mathrm{kb}$ range, resembling the early pupal transcription pattern shown in Fig. 5. Several $\operatorname{poly}(\mathrm{A})^{+}$transcripts were also detected in male and female heads and thoraces, including a 3.2-kb species, although their abundance was at least 3 orders of magnitude lower than the amounts of the transcripts in the ovaries (Fig. 6). Since the tissues were dissected by hand before RNA extraction, the low levels of transcripts detected in the heads and thoraces were not the result of contaminating RNA from other tissues.

\section{DISCUSSION}

Molecular characterization of the otu ${ }^{+}$gene region. We have detected the insertion of transposable sequences in a 0.89-kb EcoRI fragment in the hybrid-dysgenesis-induced $o t u^{P}$ alleles, and we have observed that excision of these sequences is correlated with the restoration of fertility in two independent revertants of $o t u^{P 1}$ and $o t u^{P 2}$ (Fig. 2 and 7). These results clearly indicate that the 0.89-kb EcoRI fragment in region 7F1 is part of this gene.

The molecular analysis of an additional mutation has allowed us to better define the location of $\mathrm{otu}^{+}$within the cloned 7F region DNA. An EMS-induced allele, otu ${ }^{17}$, contains a deletion of about $2 \mathrm{~kb}$ in the $2.9-\mathrm{kb}$ EcoRI fragment immediately distal to the 0.89 -kb fragment which enters the 4.7-kb EcoRI fragment distal to it (Fig. 3 and 7). The 4.7-kb EcoRI fragment contains the $s 38$ chorion gene. Therefore, the $3^{\prime}$ end of the gene lies immediately proximal to the $s 38$ chorion gene.
The $5^{\prime}$ end of the gene is not yet defined. Our Northern hybridization studies (Fig. 4) suggest that a small exon or exons exist upstream from the 0.89 -kb fragment, since very weak hybridization to a $3.2-\mathrm{kb}$ RNA is detected with two subclones $5^{\prime}$ to the $0.89-\mathrm{kb}$ EcoRI fragment.

Our molecular results are consistent with the genetic recombination and deficiency mapping experiments which have placed the $o t u^{2}$ allele approximately 0.06 centimorgan proximal to cor-36 (Digan, Ph.D. thesis), a mutation in the s36 chorion gene (Mohler, unpublished results [21]), and

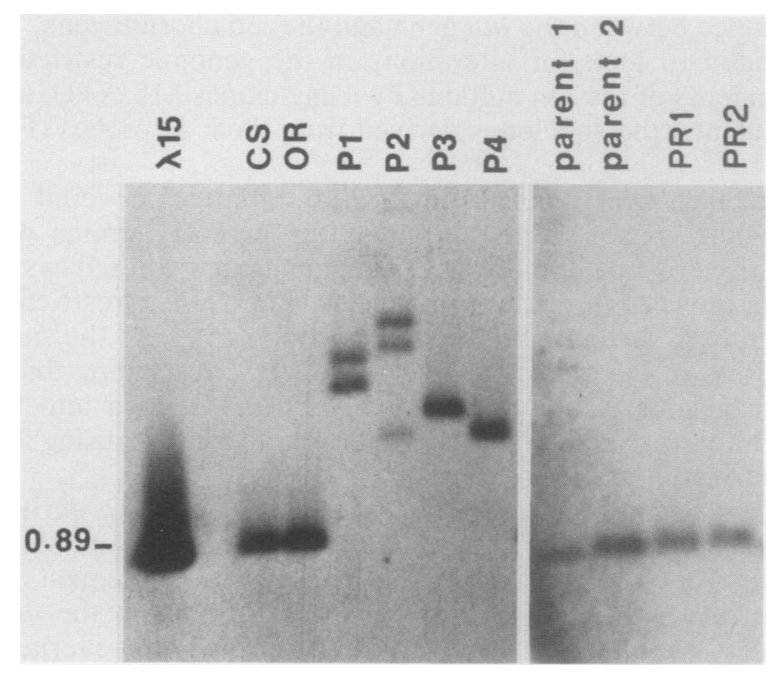

FIG. 2. Genomic restriction patterns of $o t u^{P}$ alleles, their $\mathrm{P}$ parent lines, and wild-type revertants. Genomic DNAs (approximately $3 \mu \mathrm{g}$ ) from whole flies and DNA from the recombinant phage $\lambda 15$ were restricted with $E c o R I$ and electrophoretically fractionated on $1 \%$ agarose gels. The DNA was transferred from the gels to nitrocellulose (42), and the filter was hybridized to nick-translated p15-0.89. The genotypes are indicated. Lane CS is from Canton S wild type, $O R$ is from Oregon $R$ wild type, and P1 to P4 are from flies carrying the alleles $o t u^{P 1}$, ot $u^{P 2}$, ot $u^{P 3}$, and $o t u^{P 4}$, respectively. Lane parent 1 is from strain 78.61, which was the P parent of ot $^{P 3}$ and $o t u^{P 4}$. Lane parent 2 is from strain Inbred cage 3 , which was the $P$ parent of $o t u^{P 1}$ and $o t u^{P 2}$. Lanes PR1 and PR2 are from the wild-type revertants of $o t u^{P I}$ and $o t u^{P 2}$, respectively. The sizes of the altered fragments in the P3 and P4 lanes are 1.6 and $1.5 \mathrm{~kb}$, respectively. The $0.89-\mathrm{kb}$ position is indicated at the left. 


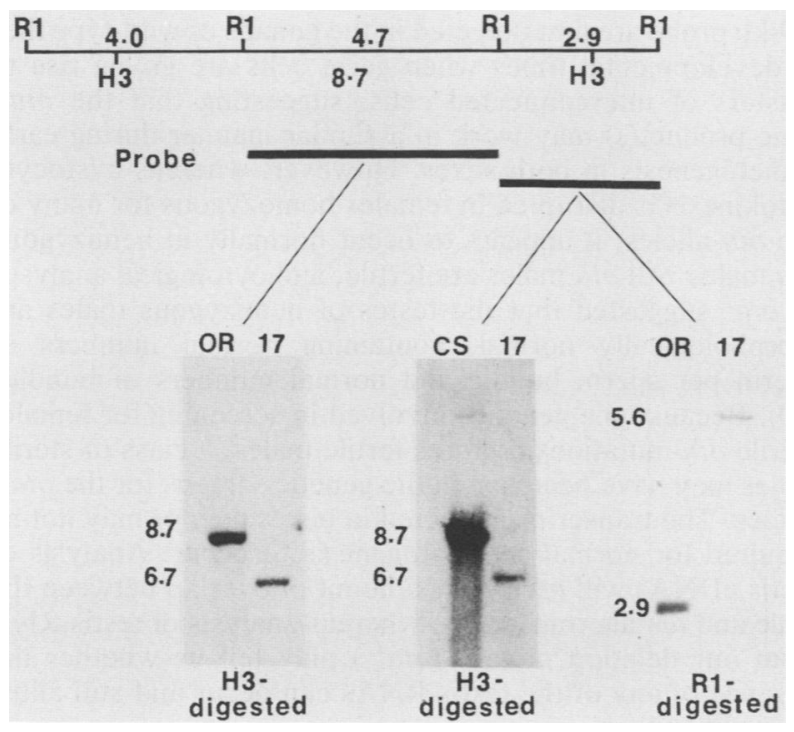

FIG. 3. Structural analysis of $o t u^{17}$. Wild-type and $o t u^{17}$ genomic DNAs $(3 \mu \mathrm{g}$ of each) were digested with either HindIII ( $\mathrm{H} 3-$ digested) or EcoRI (R1-digested), and the mutant DNA was compared with the wild-type DNA in the genomic regions drawn at the top by using radiolabeled p103.47 (43) to probe the left-hand panel and radiolabeled p15-2.9 as a hybridization tag for the two panels on the right. Pertinent restriction fragments are shown on the map at the top of the figure, and the regions that were used as probes are indicated by thick lines below the region they come from. The sizes in kilobases of the restriction fragments are given above the map for $E c o$ RI fragments and beneath the map for HindIII fragments. The 0.89-kb EcoRI fragment (not shown) lies to the right of the 2.9-kb fragment. OR (Oregon R), CS (Canton S), and 17 (otu ${ }^{17}$ ) DNAs are indicated above their lanes.

distal to $1(1) B 4$ (Digan, Ph.D. thesis). $1(1) B 4$ is allelic to the inversion $\operatorname{In}(1) R A 35$, which has a breakpoint at $7 \mathrm{~F}$. A molecular analysis of the $\operatorname{In}(1) R A 35$ breakpoint will help define a $5^{\prime}$ limit for the otu gene. Since all In(I)RA35/otu combinations that have been tested are fertile (21; Digan, Ph.D. thesis), the breakpoint must lie 5' to the gene.

It is interesting that the $o t u^{+}$DNA lies so close to another cluster of genes transcribed in the ovaries, including the $\mathrm{X}$-chromosome chorion genes. The cluster of genes transcribed in the ovaries extends distally beyond $s 36$ as well as proximally beyond $s 38$, although the more-distal genes that have been analyzed are transcribed in the follicle cells (35, 36) as the chorion genes are. Consistent with studies which suggested ot $^{+}$expression in germ cells (48), recent in situ studies show that ot $^{+}$RNA, called transcript $\mathrm{K}$, is present in the nurse cells in stage 8 to stage 10 egg chambers and that $\mathrm{otu}^{+}$RNA is contributed to the ooplasm through the cytoplasmic bridges (35). Although the 16-fold amplification in the follicle cells of the DNA surrounding the chorion genes (43) includes the 2.9- and 0.89-kb EcoRI fragments of the $\mathrm{otu}^{+}$locus, the amplification is probably fortuitous, since there is no evidence that ot $^{+}$is transcribed in the follicle cells.

Complex ot $^{+}$transcripts. We used subclones from the DNA segment containing the ot $u^{+}$gene as hybridization probes to identify $o t u^{+}$RNA and to determine which restriction fragments from the otu $u^{+}$region are homologous to ot $u^{+}$ transcripts. Our results indicate that subclones from the distal region of $\lambda 15$ detect a predominant $3.2-\mathrm{kb}$ ovarian transcript and a minor 4.0-kb transcript, whereas those from the proximal region detect additional high-molecular-weight transcripts (Fig. 4). With single-stranded RNA probes, the sensitivity of detection is increased and even the $2.9-\mathrm{kb}$ fragment hybridized to several higher-molecular-weight ovarian species (Fig. 5). One possibility for the origin of these multiple and apparently overlapping transcripts is that some of these fragments share homology with RNA transcribed from genes outside the $7 F$ region. Since the recombinant DNA clones and subclones used in this study hybridized as single-copy sequences, we do not feel that this is likely. The data in Fig. 4 and 7 imply that the 3.2-kb ovarian transcript extends at least as far as the 2.2-kb EcoRI fragment which ends $9.2 \mathrm{~kb}$ from the left or distal end of the 2.9-kb EcoRI fragment. Other ovarian Northern blots probed with moreproximal $\left(5^{\prime}\right)$ probes derived from $\lambda 403$ and $\lambda 1406$ also hybridized to 3.2- and 4.0-kb RNAs as well as to more RNA species (data not shown), and this result leaves open the possibility that the locus extends as far as $35 \mathrm{~kb}$. While $35 \mathrm{~kb}$

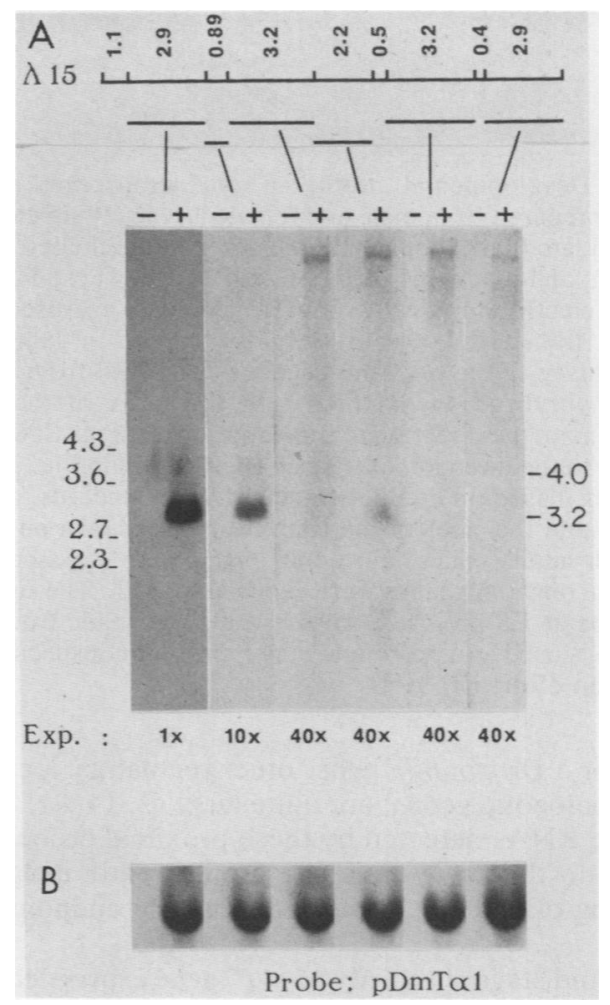

FIG. 4. Determination of the sizes of the ovarian transcripts from the otu locus. (A) Ovarian RNA was prepared from wild-type (Canton S) flies, and $4 \mu \mathrm{g}$ of RNA per lane was electrophoresed on formaldehyde-agarose gels. The nucleic acids were transferred to nitrocellulose, and each set of poly(A) ${ }^{-}$and poly $(A)^{+}$RNA was hybridized with probes generated by nick translation of the subcloned $E c o$ RI fragments from $\lambda 15$ (Fig. 1). The filters were exposed to X-ray film, and the autoradiograms are shown. The sizes in kilobases of the subcloned plasmids used as hybridization probes are indicated above the map of $\lambda 15$. Sizes in kilobases of RNAs are given at the left of the autoradiograms and are based on doublestranded DNA restriction fragment markers. Symbols: - , poly(A) ${ }^{-}$ RNA;,$+ \operatorname{poly}(A)^{+}$RNA. The relative exposure time for each RNA strip is given below the autoradiogram. (B) The same strips were washed by boiling in distilled $\mathrm{H}_{2} \mathrm{O}$ and rehybridized to the nicktranslated plasmid subclone pDmTal (16), which contains an $\alpha$ tubulin gene, to verify that the amounts of RNA loaded in each lane were constant and that the RNA was intact. 


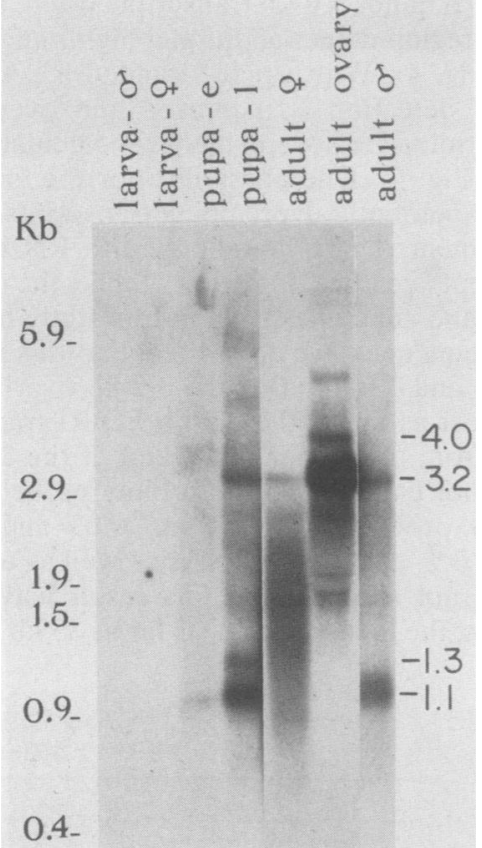

FIG. 5. Developmental profile of ot $^{+}$transcripts. Poly $(\mathrm{A})^{+}$ RNA was prepared from male and female larvae (10 $\mu \mathrm{g}$ each), early (white) and late (dark) pupae (10 $\mu \mathrm{g}$ each), adult females and males (4 $\mu \mathrm{g}$ each), and ovaries ( $1 \mu \mathrm{g})$. e, Early; 1 , late. These RNAs were separated electrophoretically on formaldehyde-agarose gels and were then transferred to nitrocellulose paper. ${ }^{32} \mathrm{P}$-labeled RNA complementary to the ot $u^{+}$message was prepared from pSP64-2.9 and was hybridized to the filter. On the basis of the genomic restriction map, the direction of transcription from the SP6 promoter is opposite to the direction of transcription shown in Fig. 1. Lengths in kilobases, based on double-stranded DNA standards, are shown at the left, and the sizes of the transcripts are shown on the right. Lanes with adult female and adult ovary were exposed for $4 \mathrm{~h}$, whereas the remaining lanes were exposed for $45 \mathrm{~h}$. The signal in the ovarian lane at $1.8 \mathrm{~kb}$ is also apparent if RNA made from plasmid SP64 alone is used as a probe and may represent nonspecific binding in the region of the rRNA.

is large for a Drosophila gene, other regulatory loci, including the homoeotic genes, are quite large $(2,14,41)$. Alternatively, the RNAs detected by these proximal probes may be unrelated to the $\mathrm{otu}^{+}$gene. We are currently isolating and sequencing cDNAs to locate the $3^{\prime}$ and $5^{\prime}$ endpoints of the gene.

Tissue and stage specificity of $o t u^{+}$gene expression. One of the surprising findings of this study is that transcripts detected by the 2.9-kb probe were expressed not only in the ovaries but also in the testes of wild-type flies. The sizes and relative abundances of the transcripts differed in the ovaries and the testes (Fig. 6 and 7). The major transcripts in the ovaries were 3.2 and $4.0 \mathrm{~kb}$, and those in the testes were 1.1 $\mathrm{kb}$ and 3.5 to $4.5 \mathrm{~kb}$. Both sets of RNAs were transcribed from the same strand, although we have not yet determined the extent of the testis-specific transcription unit. Although a 3.2-kb transcript was detected in blots of whole male flies, this message was not found in testes and must therefore have come from the body of the male.

In $D$. melanogaster, the earliest stages of gametogenesis in both sexes are remarkably similar, in that germ cells of both sexes give rise to cystoblasts, which undergo incomplete cytokinesis to generate clusters of interconnected cells $(19,29)$. Our results show that transcripts homologous to the 2.9-kb probe are first detected in the gonads of wild-type flies at developmental times when germ cells are giving rise to clusters of interconnected cells, suggesting that the $o t u^{+}$ gene product(s) may work in a similar manner during early gametogenesis in both sexes. However, whereas cystocyte cytokinesis is disrupted in females homozygous for many of the otu alleles, it appears to occur normally in hemizygous otu males. All otu males are fertile, and cytological analyses of otu $^{I}$ suggested that the testes of hemizygous males are morphologically normal, containing normal numbers of sperm per sperm bundle and normal numbers of bundles (20). Because the genetics involved in screening for femalesterile otu mutations requires fertile males, a class of sterile males may have been lost in the genetic screens for the $o t u^{+}$ alleles. The transcripts detected in testes may or may not be required for normal spermatogenesis to occur. Analysis of testis cDNAs will reveal the amount of overlap between the male and female transcripts, whereas analysis of testis RNA from our deletion mutant $\left(o t u^{17}\right)$ may tell us whether the absence of any of the testis RNAs can occur and still allow normal fertility.

$o t u^{+}$-specific transcripts were also detected in the heads and thoraces of wild-type male and female flies, although in very low amounts. The significance of these findings is unclear. However, since mutations in the $o t u^{+}$gene disrupt normal function only in the ovaries, these RNAs are either unnecessary in the other tissues or these tissues are much less sensitive to decreased amounts of the product or to less-active forms of the proteins.

The occurrence of more than one $\mathrm{otu}^{+}$transcript may arise from the use of multiple sites of initiation, polyadenylation, exon splicing, or any combination of these to give rise to multiple, partly overlapping final products. Several Dro-

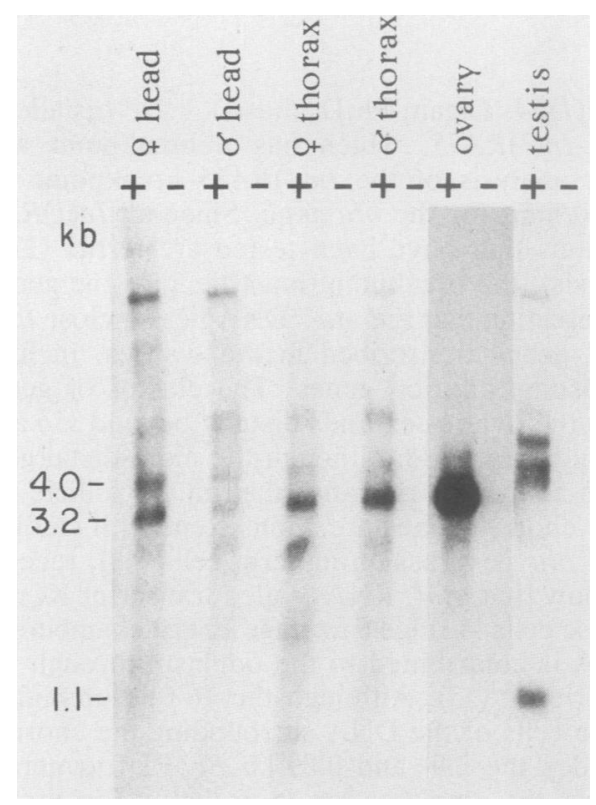

FIG. 6. Distribution of $\operatorname{otu}^{+}$RNA in the adult. Poly(A) ${ }^{+}(+)$and poly $(A)^{-}(-)$RNA from male and female heads $(3 \mu \mathrm{g}$ each), female thoraces $(5.5 \mu \mathrm{g})$, male thoraces $(4.3 \mu \mathrm{g})$, ovaries $(0.5 \mu \mathrm{g})$, and testes $(1.5 \mu \mathrm{g})$ were prepared, electrophoresed, transferred, and hybridized as described in the legend to Fig. 5. The lane containing ovary RNA was exposed for $2 \mathrm{~h}$, the lane containing testis RNA was exposed for $24 \mathrm{~h}$, and the lanes containing RNA from heads and thoraces were exposed for 7 days. Molecular sizes (in kilobases) are indicated on the left. 


$\begin{array}{lllll}\text { O'. } & & & \\ \text { HEAD AND } & 4.0 & & & \\ \text { THORAX } & 3.2 & & \\ & & & \\ \text { TESTIS } & 4.2 & & & \\ & 3.7 & & & \\ & 3.5 & & & \\ & 1.1 & & & \\ \text { OVARY } & 4.0 & 4.0 & & \\ & 3.2 & 3.2 & 3.2 & 3.2\end{array}$

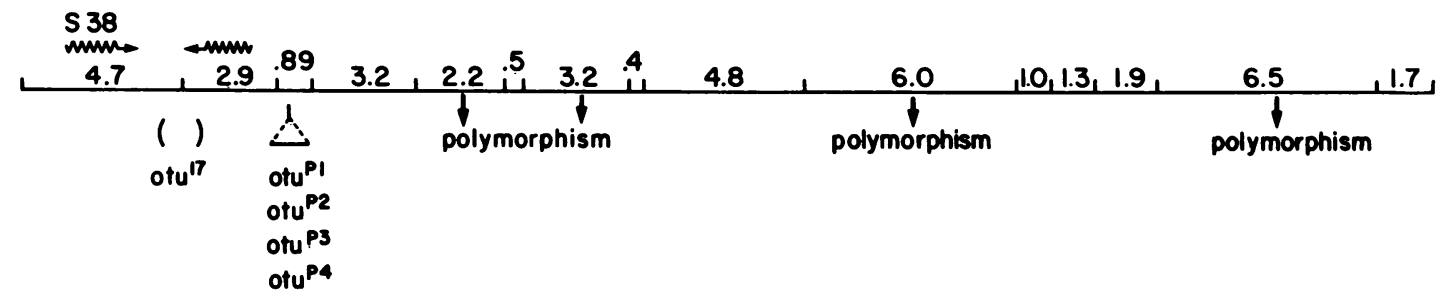

FIG. 7. Summary of genomic and transcription data. The genomic map of the ot $u^{+}$locus is shown, with the EcoRI sites and fragment sizes marked as in Fig. 1. Below the map, the positions of the genetic alterations are given. Symbols: () , deletion; $\hat{\Delta}$, insertions. The polymorphic EcoRI fragments are shown below the map. Wavy arrows just above the map reflect the positions of the transcripts and the direction of transcription. The sizes of the major RNAs (in kilobases) detected by the subclones or fragments used in this study are shown directly above the map region that bears homology to them. To the left of these numbers are indicated the adult organs or parts that contained the various transcripts. Only ovarian RNA was probed with DNA proximal to the 2.9-kb EcoRI fragment; the transcripts detected from other tissue sources may therefore extend beyond the 2.9-kb EcoRI fragment. Several other ovarian transcripts have been detected proximal to $\lambda 15$ along the length of the genomic map shown. These additional RNAs are not included in this figure or presented in the study, since their relevance to $\mathrm{otu}^{+}$has not been determined.

sophila genes transcribe multiple mRNAs, including myosin heavy chain $(4,39), 5 \mathrm{C}$ actin $(7)$, and alcohol dehydrogenase (3). The alternative RNA products from these genes are often expressed differentially in specific tissues or developmental stages and serve to generate diverse gene products from a single transcription unit.

The observation of nearly complete complementation between some otu alleles (44) suggests another possible explanation for the existence of multiple transcripts: the production of more than one $\mathrm{otu}^{+}$protein. Comparative analyses of ovarian RNAs and protein products from mutant and wildtype flies will provide a clearer understanding of the molecular events associated with otu function.

\section{ACKNOWLEDGMENTS}

We thank Gustavo Maroni, Robert C. King, Brian Kay, Patricia Maness, and John Lucchesi for helpful comments on the manuscript. We thank Allan C. Spradling for providing us with recombinant clones of the $7 \mathrm{~F}$ region.

This work was supported by Public Health Service grant GM36801 from the National Institutes of Health.

\section{LITERATURE CITED}

1. Aviv, J., and P. Leder. 1972. Purification of biologically active globin mRNA by column chromatography on oligothymidillic acid cellulose. Proc. Natl. Acad. Sci. USA 69:1408-1412.

2. Bender, W., M. Akam, F. Karch, P. Beachy, M. Peifer, P. Spierer, E. B. Lewis, and D. S. Hogness. 1983. Molecular genetics of the Bithorax complex in Drosophila melanogaster. Science 221:23-29.

3. Benyajati, C., N. Spoerel, H. Haymerle, and M. Ashburner. 1983. The messenger RNA for alcohol dehydrogenase in Drosophila melanogaster differs in its $5^{\prime}$ end in different developmental stages. Cell 33:125-133.
4. Bernstein, S. I., C. J. Hansen, K. D. Becker, D. R. Wassenberg II, E. S. Roche, J. J. Donady, and C. P. Emerson, Jr. 1986. Alternative RNA splicing generates transcripts encoding a thorax-specific isoform of Drosophila melanogaster myosin heavy chain. Mol. Cell. Biol. 6:2511-2519.

5. Bingham, P. M., M. G. Kidwell, and G. M. Rubin. 1982. The molecular basis of P-M hybrid dysgenesis: the role of the $\mathrm{P}$ element, a P-strain-specific transposon family. Cell 29:9951004.

6. Bishop, D. L., and R. C. King. 1984. An ultrastructural study of ovarian development in the ot $u^{7}$ mutant of Drosophila melanogaster. J. Cell Sci. 67:87-119.

7. Bond, B. J., and N. Davidson. 1986. The Drosophila melanogaster actin 5C gene uses two transcription initiation sites and three polyadenylation sites to express multiple mRNA species. Mol. Cell. Biol. 6:2080-2088.

8. Brown, E. H., and R. C. King. 1964. Studies on the events resulting in the formation of an egg chamber in Drosophila melanogaster. Growth 28:41-81.

9. Clewell, D. B. 1972. Nature of Col $E_{1}$ plasmid replication in Escherichia coli in the presence of chloramphenicol. J. Bacteriol. 110:667-676.

10. David, J. 1962. A new medium for rearing Drosophila in axenic conditions. Drosophila Inf. Serv. 36:128.

11. Denhardt, D. T. 1966. A membrane filter technique for the detection of complementary DNA. Biochem. Biophys. Res. Commun. 23:641-646.

12. Engels, W. R. 1983. The $P$ family of transposable elements in Drosophila. Annu. Rev. Genet. 17:315-344.

13. Gans, M., C. Audit, and M. Masson. 1975. Isolation and characterization of sex-linked female-sterile mutants in Drosophila melanogaster. Genetics 81:683-704.

14. Garber, R. L., A. Kuroiwa, and W. J. Gehring. 1983. Genomic and cDNA clones of the homeotic locus Antennapedia in Drosophila. EMBO J. 2:2027-2036.

15. Gergen, J. P., R. H. Stern, and P. C. Wensink. 1979. Filter replicas and permanent collections of recombinant DNA plas- 
mids. Nucleic Acids Res. 7:2115-2136.

16. Kalfayan, L., and P. C. Wensink. 1981. $\alpha$-Tubulin genes of Drosophila. Cell 24:97-106.

17. Kalfayan, L., and P. C. Wensink. 1982. Developmental regulation of Drosophila $\alpha$-tubulin genes. Cell 29:91-98.

18. Kidd, S., T. J. Lockett, and M. Young. 1983. The Notch locus of Drosophila melanogaster. Cell 34:421-433.

19. King, R. C. 1970. Ovarian development in Drosophila melanogaster. Academic Press, Inc., New York.

20. King, R. C., M. Bahns, R. Horowitz, and P. Larramendi. 1978. A mutation that affects female and male germ cells differentially in Drosophila melanogaster Meigen (Diptera: Drosophilidae). Int. J. Insect Morphol. Embryol. 7:359-378.

21. King, R. C., D. Mohler, S. F. Riley, P. D. Storto, and P. S. Nicolazzo. 1986. Complementation between alleles at the ovarian tumor locus of Drosophila melanogaster. Dev. Genet. 7: $1-20$.

22. King, R. C., and J. D. Mohler. 1975. The genetic analysis of oogenesis in Drosophila melanogaster. In R. C. King (ed.), Handbook of genetics, vol. 3. Plenum Publishing Corp., New York.

23. King, R. C., E. M. Rasch, S. F. Riley, P. M. O'Grady, and P. D. Storto. 1985. Cytophotometric evidence for the transformation of oocytes into nurse cells in Drosophila melanogaster. Histochemistry 82:131-134.

24. King, R. C., and S. F. Riley. 1982. Ovarian pathologies generated by various alleles of the otu locus in Drosophila melanogaster. Dev. Genet. 3:69-89.

25. King, R. C., S. F. Riley, J. D. Cassidy, P. E. White, and Y. K. Paik. 1981. Giant polytene chromosomes from the ovaries of a Drosophila mutant. Science 212:441-443.

26. Koch, E. A., and R. C. King. 1966. The origin and early differentiation of the egg chamber of Drosophila melanogaster. J. Morphol. 119:283-304.

27. Koch, E. A., and R. C. King. 1969. Further studies on the ring canal system of the ovarian cystocytes of Drosophila melanogaster. Z. Zellforsch. Mikrosk. Anat. 102:129-152.

28. Koch, E. A., P. A. Smith, and R. C. King, 1967. The division and differentiation of Drosophila cystocytes. J. Morphol. 121:55-70.

29. Lindsley, D. L., and K. T. Tokuyasu. 1980. Spermatogenesis, p. 225-294. In M. Ashburner and T. Wright (ed.), The genetics and biology of Drosophila melanogaster, vol. 2d. Academic Press, Inc. (London), Ltd., London.

30. Mahowald, A. P., and M. P. Kambysellis. 1980. Oogenesis, p. 141-224. In M. Ashburner and T. Wright (ed.), The genetics and biology of Drosophila melanogaster, vol. 2d. Academic Press, Inc. (London), Ltd., London.

31. Maniatis, T., E. F. Fritsch, and J. Sambrook. 1982. Molecular cloning: a laboratory manual. Cold Spring Harbor Laboratory, Cold Spring Harbor, N.Y.

32. Maniatis, T., R. C. Hardison, E. Lacy, J. Lauer, C. O'Connell, D. Quon, G. K. Sim, and A. Efstradiadis. 1978. The isolation of structural genes from libraries of eucaryotic DNA. Cell 15:687701.

33. Maniatis, T., A. Jefirey, and D. G. Kleid. 1975. Nucleotide sequence of the rightward operator of phage $\lambda$. Proc. Natl. Acad. Sci. USA 72:1184-1188.

34. Melton, D. A., P. A. Krieg, M. R. Rebagliati, T. Maniatis, K. Zinn, and M. R. Green. 1984. Efficient in vitro synthesis of biologically active RNA and RNA hybridization probes from plasmids containing a bacteriophage SP6 promoter. Nucleic Acids Res. 12:7035-7056.

35. Parks, S., and A. C. Spradling. 1987. Spatially regulated expression of chorion genes during Drosophila oogenesis. Genes Dev. 1:497-509.

36. Parks, S., B. Wakimoto, and A. Spradling. 1986. Replication and expression of an X-linked cluster of Drosophila chorion genes. Dev. Biol. 117:294-305.

37. Rasch, E. M., R. C. King, and R. W. Rasch. 1984. Cytophotometric studies on cells from the ovaries of otu mutants of Drosophila melanogaster. Histochemistry 81:105-110.

38. Rigby, P. W. J., M. Dieckmann, C. Rhodes, and P. Berg. 1977. Labeling of deoxyribonucleic acid to high specific activity in vitro by nick translation with DNA polymerase I. J. Mol. Biol. 113:237-251.

39. Rozek, C. E., and N. Davidson. 1983. Drosophila has one myosin heavy-chain gene with three developmentally regulated transcripts. Cell 32:23-34.

40. Rubin, G. M., M. G. Kidwell, and P. M. Bingham. 1982. The molecular basis of P-M hybrid dysgenesis: the nature of induced mutations. Cell 29:987-994.

41. Scott, M. P., A. J. Weiner, T. I. Hazelrigg, B. A. Polisky, V. Pirotta, F. Scalenghe, and T. C. Kaufman. 1983. The molecular organization of the Antennapedia locus of Drosophila. Cell 35: 763-776.

42. Southern, E. M. 1975. Detection of specific sequences among DNA fragments separated by gel electrophoresis. J. Mol. Biol. 98:503-517.

43. Spradling, A. C. 1981. The organization and amplification of two chromosomal domains containing Drosophila chorion genes. Cell 27:193-201.

44. Storto, P. D., and R. C. King. 1987. Fertile heteroallelic combinations of mutant alleles of the otu locus of Drosophila melanogaster. Wilhelm Roux's Arch. Dev. Biol. 196:210-221.

45. Thomas, M., and R. W. Davis. 1975. Studies on the cleavage of bacteriophage lambda with Eco RI restriction endonuclease. J. Mol. Biol. 91:315-328.

46. Thomas, P. S. 1980 . Hybridization of denatured RNA and small DNA fragments transferred to nitrocellulose. Proc. Natl. Acad. Sci. USA 77:5201-5205.

47. Wakimoto, B. T., L. J. Kalfayan, and A. C. Spradling. 1986. Developmentally regulated expression of Drosophila chorion genes introduced at diverse chromosomal positions. J. Mol. Biol. 187:33-45.

48. Wieschaus, E., C. Audit, and M. Masson. 1981. A clonal analysis of the roles of somatic cells and germ line during oogenesis in Drosophila. Dev. Biol. 88:92-103.

49. Zinn, K., D. DiMaio, and T. Maniatis. 1983. Identification of two distinct regulatory regions adjacent to the human $\beta$-interferon gene. Cell 34:865-879. 